\title{
Targeted approach to identify genetic loci associated with evolved dioxin tolerance in Atlantic Killifish (Fundulus heteroclitus)
}

Dina A Proestou ${ }^{1,3^{*}}$, Patrick Flight $^{2 \dagger}$, Denise Champlin ${ }^{1 \dagger}$ and Diane Nacci ${ }^{1}$

\begin{abstract}
Background: The most toxic aromatic hydrocarbon pollutants are categorized as dioxin-like compounds (DLCS) to which extreme tolerance has evolved independently and contemporaneously in (at least) four populations of Atlantic killifish (Fundulus heteroclitus). Surprisingly, the magnitude and phenotype of DLC tolerance is similar among these killifish populations that have adapted to varied, but highly aromatic hydrocarbon-contaminated urban/industrialized estuaries of the US Atlantic coast. Multiple tolerant and neighboring sensitive killifish populations were compared with the expectation that genetic loci associated with DLC tolerance would be revealed.

Results: Since the aryl hydrocarbon receptor (AHR) pathway partly or fully mediates DLC toxicity in vertebrates, single nucleotide polymorphisms (SNPs) from 42 genes associated with the AHR pathway were identified to serve as targeted markers. Wild fish ( $N=36 / 37)$ from four highly tolerant killifish populations and four nearby sensitive populations were genotyped using 59 SNP markers. Similar to other killifish population genetic analyses, strong genetic differentiation among populations was detected, consistent with isolation by distance models. When DLC-sensitive populations were pooled and compared to pooled DLC-tolerant populations, multi-locus analyses did not distinguish the two groups. However, pairwise comparisons of nearby tolerant and sensitive populations revealed high differentiation among sensitive and tolerant populations at these specific loci: AHR 1 and 2, cathepsin Z, the cytochrome P450s (CYP1A and 3A30), and the NADH dehydrogenase subunits. In addition, significant shifts in minor allele frequency were observed at AHR2 and CYP1A loci across most sensitive/tolerant pairs, but only AHR2 exhibited shifts in the same direction across all pairs.

Conclusions: The observed differences in allelic composition at the AHR2 and CYP1A SNP loci were identified as significant among paired sensitive/tolerant populations of Atlantic killifish with multiple statistical tests. The genetic patterns reported here lend support to the argument that AHR2 and CYP1A play a role in the adaptive response to extreme DLC contamination. Additional functional assays are required to isolate the exact mechanism of DLC tolerance.
\end{abstract}

Keywords: Adaptation, Ecotoxicology, Candidate gene scan, Killifish

\footnotetext{
* Correspondence: dina.proestou@ars.usda.gov

${ }^{\dagger}$ Equal contributors

'US Environmental Protection Agency, Office of Research and Development,

National Health and Environmental Effects Research Laboratory, Atlantic

Ecology Division, 27 Tarzwell Drive, Narragansett, RI 02882, USA

${ }^{3}$ Current address: USDA Agricultural Research Service, 469 Center for

Biotechnology and Life Sciences, 120 Flagg Road, Kingston, RI 02881, USA

Full list of author information is available at the end of the article
} 


\section{Background}

Dioxin-like contaminants (DLCs), such as some polychlorinated biphenyls (PCBs), are highly toxic aromatic hydrocarbon pollutants whose ubiquitous occurrence presents global ecological and human health risks. The early life stages of fish are particularly sensitive to these toxic DLCs, and the Atlantic killifish, Fundulus heteroclitus, is one of the more sensitive fish species [1]. Despite this species' relative sensitivity to DLC exposure, several wild killifish populations residing in heavily contaminated North American Atlantic coast estuaries have recently and independently evolved dramatic, heritable, and adaptive tolerance to DLCs [2], for which the mechanistic basis has yet to be fully explained. To address this issue, a targeted, candidate gene scan was performed to reveal genetic variation associated with tolerance in four wild DLC-adapted killifish populations.

Considerable effort has been spent attempting to identify the genetic and biochemical mechanisms underlying inter- and intra-specific variation in DLC sensitivity in vertebrates. Multiple lines of evidence support the crucial role of the aryl hydrocarbon receptor (AHR) pathway in DLC toxicity in mammals. Polymorphisms in the ligand binding domain of the AHR among mouse strains result in differences in ligand binding affinity, and low binding affinity appears to protect against all toxic responses to DLCs. In rats, DLC tolerance is associated with variation in the transactivation domain of the AHR, yet functional consequences of the variation are less predictable [3]. A candidate gene approach effectively identified two amino acid substitutions in the AHR among avian wildlife and a consistent relationship between the amino acid residues present and DLC sensitivity was observed at the species level $[4,5]$. In fish, the striking difference in DLC sensitivity among wild Atlantic tomcod populations has been attributed to a six base pair deletion in the AHR2 gene that results in a five-fold decrease in ligand binding affinity and reduced ability to promote expression of detoxification enzymes targeted by the AHR pathway [6].

Within the killifish AHR pathway, several nonsynonymous single nucleotide polymorphisms (SNPs) have been identified in two AH receptor genes (AHR1 and AHR2), but patterns of genetic variation at these loci do not unequivocally reflect differences in DLC sensitivity among populations and no functional consequences (i.e., ligand binding and the ability to interact with xenobiotic metabolizing enzymes) were associated with AHR1 variants [7-9]. As an alternative to the candidate gene approach, Williams and Oleksiak [10,11] performed whole genome scans, whereby patterns of variation across hundreds of genetic loci were contrasted between killifish populations from polluted and reference sites in order to identify genes under selection with respect to DLC contamination. A handful of selectively important genetic markers were identified in each of three separate comparisons between populations residing in polluted habitats and their respective reference populations, and a single marker (in the CYP1A promoter) was found to be selectively important in all comparisons.

Both the single candidate gene approach and genomewide scans (typically with sets of anonymous genetic markers) have led to great success in elucidating the genetic basis for many adaptive phenotypes $[12,13]$, but neither has offered a comprehensive link to the observed variation in DLC sensitivity among wild killifish populations. A 'candidate gene scan' approach, which targets a relatively large set of expressed genes with known physiological function, should increase the probability of isolating genes that are under selection and relevant with respect to traits of interest [14]. Thus, this approach was adopted to maximize efficiency in the identification of genes associated with DLC tolerance, and complement previous and ongoing work investigating the mechanism(s) involved in the repeated adaptation to DLCs in wild killifish populations.

In this study, patterns of genetic variation at SNP markers distributed across genes that are components of, or whose expression is affected by the AHR and interacting pathways were examined among eight killifish populations that vary genetically in their responsiveness to DLCs. Four relatively uncontaminated populations whose sensitivities to a prototypical DLC $\left(3,3^{\prime}, 4,4^{\prime}, 5\right.$ - pentachlorobiphenyl, PCB126) range from $20-38 \mathrm{ng} / \mathrm{L}$ (reviewed in [12]) were chosen as sensitive populations. Each of these populations is located near one of four EPA-designated urban/industrial estuarine Superfund sites. Killifish resident to these sites are dramatically tolerant to the effects of PCB126, displaying LC20 values ranging from $~ 400$ to $\sim 8000$ times higher than those for the sensitive killifish (Table 1). A companion study [9] provides a fine-scaled examination of genetic variation in three AHR-related loci (AHR1, AHR2, and AHRR) among killifish populations residing in uncontaminated and polluted habitats of the North Atlantic coast of the US, including some of the same populations examined in this study.

The question of whether the genetic variants observed at the targeted SNP markers in this study could explain the stark phenotypic differences between DLC-adapted (-tolerant) and -sensitive killifish populations was addressed in several ways. Measures of genetic diversity were compared between DLC-sensitive and DLC- tolerant groups and patterns of genetic differentiation among populations were tested against expectations of isolation by distance. In addition, by contrasting the behavior of individual loci among DLC-sensitive and DLC-tolerant populations, specific loci under selection were identified. 
Table 1 Killifish population locations and site characteristics

\begin{tabular}{|c|c|c|c|c|c|c|}
\hline Site ID & Site location & Latitude $\times$ Longitude $(\mathrm{W})$ & $\begin{array}{l}\text { Distance from NBH, } \\
\text { latitude, km }\end{array}$ & $\begin{array}{l}\text { Latitudinal distance } \\
\text { between pairs, km }\end{array}$ & $\begin{array}{l}\text { LC20 (log), } \\
\text { ng PCB126/L }\end{array}$ & DLC responsiveness \\
\hline NBH & New Bedford, MA & $41.6676 \times 70.9159$ & 0 & 56 & 4.6 & Tolerant \\
\hline $\mathrm{Bl}$ & Block Island, RI & $41.1818 \times 71.5793$ & 56 & & 1.4 & Sensitive \\
\hline BP & Bridgeport, CT & $41.1570 \times 73.2189$ & 63 & 22 & 4.1 & Tolerant \\
\hline FLAX & Flax Pond, NY & $40.9637 \times 73.1342$ & 85 & & 1.6 & Sensitive \\
\hline NWK & Newark, NJ & $40.7006 \times 74.1223$ & 115 & 26 & 4.1 & Tolerant \\
\hline $\mathrm{SH}$ & Sandy Hook, NJ & $40.4687 \times 74.0113$ & 141 & & 1.3 & Sensitive \\
\hline ER & Portsmouth, VA & $36.8078 \times 76.2945$ & 547 & 55 & 5.3 & Tolerant \\
\hline KC & Gloucester, VA & $37.3016 \times 76.4226$ & 492 & & 1.4 & Sensitive \\
\hline
\end{tabular}

Taken from Nacci et al. 2010. LC20 values represent the concentration of PCB126 resulting in 20\% lethality of killifish embryos.

\section{Methods}

\section{SNP marker development and preliminary screening}

An extensive literature search was conducted to identify genes and biochemical pathways with demonstrated and potential involvement in the toxic responses to DLCs. A list of over 150 genes was compiled, which included components of the AHR pathway, nuclear receptors known to 'cross talk' with the AHR pathway (i.e., estrogen receptors, retinoic acid receptors, hypoxia inducible factors), cytochrome p450s, genes involved in cardiac development, cathepsins, and genes having oxidoreductase activity (e.g. [15], and references therein). The gene list was filtered at several stages of the marker development process. Sequence information for many, but not all, of the genes listed in Additional file 1 was retrieved from the $F$. heteroclitus unigene database in GenBank (http://www.ncib.nlm.nih.go/GenBank/). Additional unpublished sequences were kindly provided by Sibel Karchner (personal communication). Putative SNPs were detected with the QualitySNP pipeline [16]. In QualitySNP, sequences with $>95 \%$ similarity were assembled into contiguous sequences (contigs) using the sequence assembly program CAP3. Available contigs, those containing $\geq 4$ overlapping sequences, were then evaluated for polymorphisms. Available contigs with SNPs were subjected to further scrutiny to assess the reliability of the putative SNPs identified. Specifically, SNPs were considered 'true' if they were represented in $\geq 2$ ESTs, paralogous sequences within the cluster could be distinguished and haplotypes identified, and they were located in high quality sequence regions [16]. PCR primers and melting temperature $\left(\mathrm{T}_{\mathrm{m}}\right)$-shift genotyping assays [17] were then designed for the 'true' SNPs with suitable flanking sequence (e.g. no SNPs, low sequence complimentarity in priming sites). A test panel of eight killifish from two populations (BI and $\mathrm{NBH}$ ) was genotyped at 128 of the loci deemed highly reliable by QualitySNP. A SNP maker was considered valid if amplification product of the appropriate size was generated and polymorphism was observed among the eight individuals in the test panel. Outcomes for each stage of the SNP marker development process are detailed in Additional file 1.

\section{Fish collection}

During the summer and fall months between 2008 and 2011, adult Fundulus heteroclitus were collected using baited minnow traps from eight estuarine sites spanning approximately $600 \mathrm{~km}$ of the Atlantic Coast of the USA (Figure 1). These specific killifish populations had already been characterized as either DLC-tolerant or DLC-sensitive, based on early life stage sensitivity to PCB126 $[2,18,19]$. To better assess genetic differences between tolerant and sensitive populations absent geographic influences, each DLC-tolerant population was paired with a nearby DLC-sensitive population. These pairs are located within the same or adjacent states but are separated by discontinuous shoreline and deep channels that limit fish migration and contaminant spread. Latitudinal distances between killifish residence sites (Table 1) were used to provide a consistent proxy to assess regional influences but were not intended to convey 'asthe-fish-swims' distances. Sixty to 100 live or sacrificed/ frozen fish from each population were transported to the US Environmental Protection Agency (EPA) laboratory in Narragansett, RI, USA. Those that were transported live were sacrificed immediately upon return to the laboratory. Whole fish were stored at either -20 or $-80^{\circ} \mathrm{C}$ prior to DNA extraction.

\section{Sample preparation and population genotyping}

Genomic DNA was extracted from approximately $20 \mathrm{mg}$ of caudal fin tissue from 36 or 37 of the 60-100 archived individuals per population according to the QIAGEN DNeasy protocol for animal tissue (optional RNase treatment included), quantified with the PicoGreen dsDNA assay (Invitrogen), and diluted to a standard concentration of $20 \mathrm{ng} / \mu \mathrm{l}$. Diluted DNA extracts were submitted to the University of Minnesota's BioMedical Genomics Center in a 96-well format for sample quality assessment and SNP genotyping using the Sequenom MassARRAY ${ }^{\odot}$ 


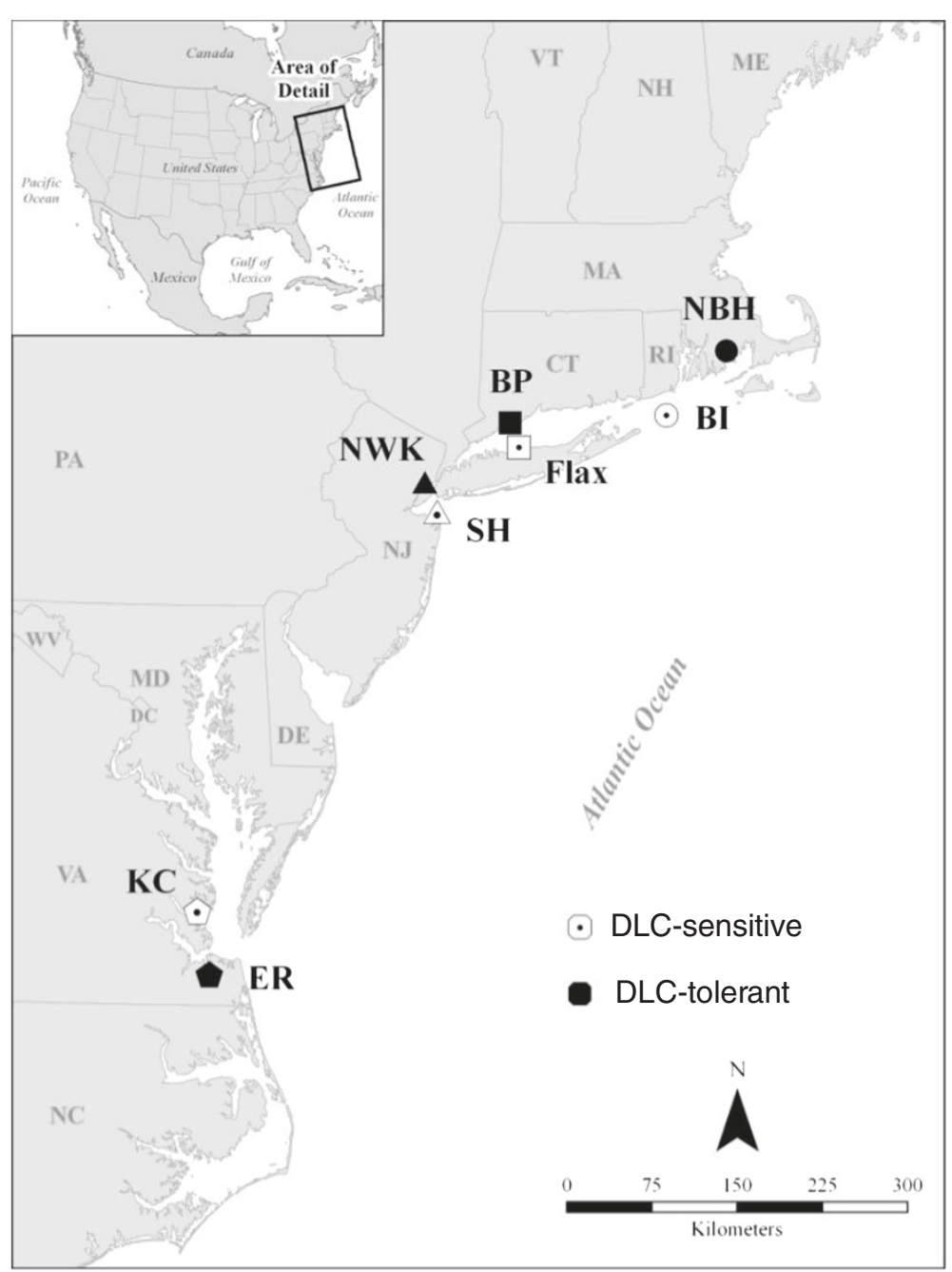

Figure 1 Map of Fundulus heteroclitus collection sites along the Eastern U.S. coast.

technology. Three multiplex assays (containing 32, 27, and 12 SNPs respectively) were designed using MassARRAY ${ }^{\circ}$ Designer software. Sampled $F$. heteroclitus for which DNA was extracted were genotyped with the first two plexes (because all SNP containing genes were represented) following the iPLEX assay protocol. Genotypes for each individual at each locus were called using the Sequenom System Typer Analysis package.

\section{Data analysis}

Routine population genetics analyses were conducted using the freely available software package Arlequin ver. 3.5 [20]. Standard diversity indices, including the percentage of polymorphic loci $\left(\mathrm{P}_{\mathrm{O}}\right)$, average observed and expected heterozygosities $\left(\mathrm{H}_{\mathrm{O}}\right.$ and $\left.\mathrm{H}_{\mathrm{E}}\right)$, and the within population fixation index $\left(\mathrm{F}_{\mathrm{IS}}\right)$, were determined for each sampled population. Indices were based on data from loci with $<10 \%$ missing data. Loci were also tested for departures from Hardy-Weinberg equilibrium (HWE) with 100,000 permutations and the percentage of loci in HWE was calculated for each population. The ability of this suite of SNP markers to detect genetic differentiation among populations was assessed by computing pairwise multi-locus $\mathrm{F}_{\mathrm{ST}}$ estimates. To test whether the assumption of independence among loci would be violated by including multiple SNPs per gene in the analysis, data from a subset of SNPs (representing one SNP per gene) were also analyzed. Results did not differ significantly between the complete and limited datasets; therefore, only results from the complete dataset are reported here.

Genetic structure, where populations were assigned to groups defined by DLC sensitivity, was also included in the analysis and the pairwise multi-locus $\mathrm{F}_{\mathrm{ST}}$ between the two groups was estimated with the 'Compute pairwise $\mathrm{F}_{\mathrm{ST}}$ ' option in Arlequin ver. 3.5. An analysis of molecular variance (AMOVA) was performed to better understand how the observed genetic variance was partitioned within populations, among populations within each group, and 
between groups. In addition, as in [9], Student's T-tests were used to detect significant differences in genetic diversity measures $\left(\mathrm{P}_{\mathrm{O}}\right.$ and $\left.\mathrm{H}_{\mathrm{O}}\right)$ among the two groups.

For species like $F$. heteroclitus that are non-migratory, genetic differences at neutral loci should accumulate over time and generate a pattern of isolation by distance (IBD), whereby differentiation among populations increases with geographic distance [21]. Deviations from IBD patterns can be attributed to responses to local selection pressures [22]. Mantel tests and reduced major axis (RMA) regression analyses were performed in Isolation By Distance Web Service (IBDWS) [23] with 10,000 permutations to test for significant correlations between genetic distance (pairwise multi-locus $\mathrm{F}_{\mathrm{ST}}$ values) and latitudinal distance. Mantel tests were also used to test for significant correlations between pairwise genetic differences and relative differences in sensitivity to PCB126 (LC20 as reported in [2]); moreover, partial Mantel tests were conducted to determine if there was a significant relationship between sensitivity to PCB126 and genetic divergence after taking latitudinal distance into account.

Although most of the genes included in this analysis were chosen based on prior work suggesting they might be responsive to DLCs, whether any or all contribute to the adaptive phenotype remains largely unresolved. To identify selectively important SNPs among the genes surveyed, $\mathrm{F}_{\mathrm{ST}}$ values were calculated at each locus separately for each sensitive/tolerant comparison with the AMOVA function in Arlequin ver. 3.5. The statistical significance of each $\mathrm{F}_{\mathrm{ST}}$ was determined through permutation testing with 10,000 iterations. An $\mathrm{F}_{\mathrm{ST}}$ modeling approach similar to that described in [24] as implemented in Arlequin ver. 3.5 was also used to detect outliers. $\mathrm{F}_{\mathrm{ST}}$ distributions conforming to a neutral model were simulated with 20,000 iterations, heterozygosities computed from empirical data, and assuming 10 demes. SNPs with $\mathrm{F}_{\mathrm{ST}}$ values exceeding the 95th percentile of the null distribution were considered to be strong candidates for natural selection. In addition, as in [12], minor allele frequencies were calculated at each locus for each population with the expectation that loci associated with the adaptive phenotype would display shifts in allele frequency for each sensitive/ tolerant pair. Consistent shifts in the same direction across all four comparisons were considered further evidence for selection acting at the loci.

\section{Results}

SNP markers

Killifish sequences representing 125 of the 150 candidate genes were mined from the GenBank nucleotide and unigene databases. CAP3 assembled those sequences into 183 contigs, of which 105 were available for further analysis (met the criterion of containing four or more overlapping sequences). Approximately 500 highly reliable putative
SNP loci distributed among 50 genes were identified with the QualitySNP pipeline. $\mathrm{T}_{\mathrm{m}}$-shift genotyping assays were designed for 128 of the highly reliable putative SNPs and the validity of each locus was tested by genotyping eight killifish collected from two populations (BI and $\mathrm{NBH}$ ) (Additional file 1). Twenty-four of the 128 putative SNPs assayed (19\%) did not amplify or produced uninterpretable melting curves. An additional 29 of the SNPs tested (23\%) appeared to be monomorphic. Ultimately, 75 (59\%) of the putative SNPs screened were polymorphic and 59 (those represented in the first two iplex assays) were used in the population genetic analysis (Table 2).

\section{Standard diversity indices}

Substantial genetic variation was observed in each killifish population examined. The percentage of polymorphic loci $\left(\mathrm{P}_{\mathrm{O}}\right)$ ranged from $51 \%$ to $73 \%$ across populations, with a greater percentage of monomorphic loci in $\mathrm{NBH}$ and the Virginia populations. A similar pattern was detected when observed heterozygosity $\left(\mathrm{H}_{\mathrm{O}}\right)$ was used to measure diversity; ER, $\mathrm{KC}$ and $\mathrm{NBH}$ populations were the least heterozygous. According to the average within population fixation index $\left(\mathrm{F}_{\mathrm{IS}}\right)$, the loss of heterozygosity in $\mathrm{NBH}, \mathrm{ER}$, $\mathrm{KC}$, and $\mathrm{SH}$ was statistically significant (Table 3 ).

A majority of the 59 SNP loci assayed (64\%) were considered to be common SNPs, with minor allele frequencies greater than 0.1, when data from all populations were pooled. For each population, the percentage of common SNPs ranged from $54 \%$ to $76 \%$ with $\mathrm{BP}$ and ER at the two extremes. Within each population the minor allele frequency, averaged across all polymorphic loci, varied between 0.16 and 0.22 . The mean minor allele frequency was lowest in BP and BI fish and highest in ER fish (Table 3).

Most of the SNP loci in this study were found to be in Hardy-Weinberg equilibrium within each population. Again, the population with the fewest loci conforming to Hardy-Weinberg expectations was ER (Table 3). In total, 14 loci deviated from HWE, but no single deviation was consistent across all eight populations or across the four tolerant populations.

\section{Genetic differentiation}

Mean pairwise $\mathrm{F}_{\mathrm{ST}}$ values for all population comparisons were found to be statistically significant and suggest moderate to very high levels of genetic differentiation. Overall, markedly higher genetic differentiation was detected between the two Virginia populations and all others (Figure 2). A standard analysis of molecular variance (AMOVA) confirmed that a substantial proportion (23\%) of the observed molecular variation can be attributed to differences among populations.

No significant differentiation emerged when populations were grouped by DLC sensitivity. The expectation that, on 
Table 2 List of SNP containing candidate genes included in the population genetic analysis

\begin{tabular}{|c|c|c|c|}
\hline Gene name & Unigene ID & Putative function & Reference \\
\hline Aryl hydrocarbon receptor 1 & 1743961[uid] & transcription factor, response to xenobiotic stimulus & [7] \\
\hline Aryl hydrocarbon receptor 2 & 1743966[uid] & transcription factor, response to xenobiotic stimulus & [8] \\
\hline Aryl hydrocarbon receptor $2 \mathrm{~b}$ & N/A & transcription factor, response to xenobiotic stimulus & $\begin{array}{l}\text { Karchner \& Hahn, } \\
\text { unpublished; }\end{array}$ \\
\hline Aryl hydrocarbon receptor repressor & 1743962[uid] & signal transducer, response to xenobiotic stimulus & [25] \\
\hline Atrial natriuretic peptide & $1743159[$ uid] & receptor binding, cardiac muscle hypertrophy in response to stress & [26] \\
\hline $\begin{array}{l}\text { Aldehyde dehydrogenase family } 9 \\
\text { member A1 }\end{array}$ & 1741825[uid] & oxidoreductase activity, retinoic acid metabolic process & {$[27]$} \\
\hline Cardiac myosin light chain-1 & $1741781[$ uid] & calcium ion binding, cardiac muscle tissue development & \\
\hline Cathepsin E precursor & 1744072[uid] & endopeptidase, antigen processing & \\
\hline Cathepsin F precursor & 1741927[uid] & cysteine-type peptidase activity & \\
\hline Cathepsin Z precursor & $2476770[$ uid $]$ & cysteine-type peptidase activity, angiogenesis & \\
\hline Complement Component C3 & 1742328[uid] & $\begin{array}{l}\text { protein binding, lipid binding, endopeptidase inhibitor, innate immune } \\
\text { response, regulation of angiogenesis }\end{array}$ & {$[28]$} \\
\hline Cytochrome p450 1A & 2476796[uid] & oxidoreductase activity, dibenzo-p-dioxin catabolic process & {$[11,29-31]$} \\
\hline Cytochrome p450 3A30 & 1742582[uid] & oxidoreductase activity, response to xenobiotic stimulus & [28] \\
\hline Cytochrome B5 & 1743444[uid] & enzyme binding, heme binding, oxidation reduction process & [29-31] \\
\hline Estrogen Receptor alpha & 1743972[uid] & $\begin{array}{l}\text { estrogen receptor activity, transcription factor binding, response to estradiol } \\
\text { stimulus, regulation of retinoic acid receptor signalling pathway }\end{array}$ & {$[32]$} \\
\hline Estrogen Receptor beta a & 2301213[uid] & $\begin{array}{l}\text { estrogen receptor activity, estrogen response element binding, response to } \\
\text { estradiol stimulus, regulation of transcription factor activity }\end{array}$ & {$[32]$} \\
\hline $\begin{array}{l}\text { Glyceraldehyde } 3 \text { phosphate } \\
\text { dehydrogenase }\end{array}$ & 1742899[uid] & oxidation reduction process & \\
\hline Hepcidin & $1744101[$ uid] & hormone activity, defense response & \\
\hline Hepcidin 2 & N/A & & $\begin{array}{l}\text { Karchner \& Hahn, } \\
\text { unpublished }\end{array}$ \\
\hline Heatshock protein 90 beta & 1743580[uid] & protein binding, response to stress & \\
\hline Plasma Kallikrein precursor & 1742469[uid] & peptidase activity, proteolysis, hemostasis & \\
\hline Kallikrein & N/A & & $\begin{array}{l}\text { Karchner \& Hahn, } \\
\text { unpublished }\end{array}$ \\
\hline Myosin Light chain 2 & 1743984[uid] & actin monomer binding, heart development & [29] \\
\hline $\begin{array}{l}\text { Myosin Light chain alkali, smooth } \\
\text { muscle }\end{array}$ & 1743182[uid] & structural constituent of muscle, muscle contraction & \\
\hline $\begin{array}{l}\text { NADH [ubiquinone] dehydrogenase } \\
1 \text { alpha subcomplex subuint } 4\end{array}$ & 1743852[uid] & electron transport chain & {$[28]$} \\
\hline Myosin regulatory light chain 3 & 1741657[uid] & calcium ion binding & \\
\hline NADH dehydrogenase subunit 1 & 3014035[uid] & oxidoreductase activity & \\
\hline $\begin{array}{l}\text { NADH dehydrogenase [ubiquinone] } \\
1 \text { beta subcomplex subunit } 10\end{array}$ & 1743800[uid] & electron transport chain & [33] \\
\hline NADH dehydrogenase subunit 2 & $1742301[$ uid] & oxidoreductase activity & \\
\hline NADH dehydrogenase subunit 3 & 1742764[uid] & oxidoreductase activity & \\
\hline NADH dehydrogenase subunit 4 & 1741822[uid] & oxidoreductase activity & \\
\hline NADH dehydrogenase subunit 6 & 3014152[uid] & oxidoreductase activity & \\
\hline Platelet Coagulation Factor XI & $3014242[$ uid] & peptidase activity, proteolysis, hemostasis & [28] \\
\hline $\begin{array}{l}\text { Retinoic Acid Receptor Responder } \\
\text { Protein } 1\end{array}$ & 1743266[uid] & negative regulation of cell proliferation & \\
\hline $\begin{array}{l}\text { Retinoic Acid Receptor Responder } \\
\text { Protein } 3\end{array}$ & 1741754[uid] & negative regulation of cell proliferation & \\
\hline
\end{tabular}


Table 2 List of SNP containing candidate genes included in the population genetic analysis (Continued)

\begin{tabular}{|c|c|c|c|}
\hline Rho-class Glutathione S-Transferase & 1743333[uid] & transferase activity & {$[30,31,34]$} \\
\hline Serine Protease Inhibitor & N/A & negative regulation of endopeptidase activity & $\begin{array}{l}\text { Karchner \& Hahn, } \\
\text { unpublished }\end{array}$ \\
\hline TBT Binding Protein & 1741555[uid] & response to xenobiotic stimulus & {$[28]$} \\
\hline Thioredoxin & 1743303[uid] & protein binding, oxidoreductase activity & {$[33]$} \\
\hline Translation Initiation Factor 2 & 1744423[uid] & $\begin{array}{l}\text { ligand-dependent nuclear receptor binding, estrogen receptor binding, } \\
\text { retinoic acid receptor binding, signal transduction }\end{array}$ & \\
\hline Telethonin (Titin cap protein) & 1743784[uid] & $\begin{array}{l}\text { heart development, cardiac muscle contraction, sarcomere organization, } \\
\text { response to stress }\end{array}$ & [29] \\
\hline Cardiac Troponin T2 & 1742146[uid] & $\begin{array}{l}\text { actin binding, tropomyosin binding, troponin binding, cardiac muscle } \\
\text { morphogenesis, sarcomere organization, muscle filament sliding }\end{array}$ & {$[26,29,35]$} \\
\hline $\begin{array}{l}\text { Ubiquitin A-52 residue ribosomal } \\
\text { protein fusion product } 1\end{array}$ & 1744070[uid] & structural constituent of ribosome, translation & \\
\hline
\end{tabular}

Note: Potential involvement of each gene in toxic DLC response was demonstrated in citations listed in 'Reference' column. $\mathrm{N} / \mathrm{A}=$ not available.

average, DLC-adapted populations are less diverse (as quantified by $\mathrm{P}_{\mathrm{O}}$ and $\mathrm{H}_{\mathrm{O}}$ ) than DLC-sensitive populations, was not supported (Table 4). The genetic differentiation between the two groups as measured by $\mathrm{F}_{\mathrm{ST}}$ was 0.0212 ; however, the hierarchical AMOVA results suggest that the groups were not significantly different (Table 5).

\section{Isolation by distance}

A regression of the genetic and latitudinal distance matrices when all populations were included in the analysis was statistically significant $(\mathrm{r}=0.8607, \mathrm{p}<0.001)$ reflecting a pattern of IBD (Figure 3A). Given that populations were sampled from three distinct geographic regions differentially impacted by the Pleistocene glacial retreat, the observed relationship is most likely driven by long-term history and demography rather than

Table 3 Genetic parameters for sampled $F$. heteroclitus populations

\begin{tabular}{lllllll}
\hline Population & $\mathbf{P}_{\mathbf{O}}$ & $\mathrm{H}_{\mathrm{O}}$ & $\mathrm{H}_{\mathrm{E}}$ & $\% \mathrm{HWE}$ & $\mathrm{F}_{\mathbf{I S}}$ & $\mathrm{MAF}$ \\
\hline $\mathrm{BI}$ & $65.31(49)$ & 0.15 & 0.15 & 71.88 & 0.042 & 0.16 \\
$\mathrm{NBH}$ & $53.19(47)$ & 0.14 & 0.16 & 76.00 & $0.171^{*}$ & 0.20 \\
$\mathrm{BP}$ & $64.58(48)$ & 0.15 & 0.15 & 93.55 & 0.001 & 0.16 \\
$\mathrm{FLAX}$ & $61.22(49)$ & 0.16 & 0.17 & 90.00 & 0.059 & 0.19 \\
$\mathrm{SH}$ & $73.33(45)$ & 0.16 & 0.21 & 78.79 & $0.240^{*}$ & 0.19 \\
$\mathrm{NWK}$ & $64.58(48)$ & 0.15 & 0.16 & 80.65 & 0.031 & 0.19 \\
ER & $51.02(49)$ & 0.12 & 0.15 & 60.00 & $0.108^{*}$ & 0.21 \\
KC & $57.14(49)$ & 0.14 & 0.17 & 82.14 & $0.122^{*}$ & 0.22 \\
Mean & 61.30 & 0.15 & 0.17 & 79.12 & 0.097 & 0.19 \\
Standard Deviation & 7.28 & 0.01 & 0.02 & 10.46 & 0.080 & 0.02 \\
\hline Po number of polymm & & &
\end{tabular}

$\mathrm{P}_{\mathrm{O}}=$ number of polymorphic loci/number of usable loci (in parentheses); $\mathrm{H}_{\mathrm{O}}=$ sum of observed heterozygosity for each usable locus/number of usable loci; $\mathrm{H}_{\mathrm{E}}=$ sum of expected heterozygosity for each usable locus/number of usable loci; \% HWE = number of loci in Hardy-Weinberg equilibrium/number of polymorphic loci; $F_{I S}=$ population specific fixation index; $M A F=$ average Minor Allele Frequency, calculated for polymorphic loci only. ${ }^{*} \mathrm{p} \leq 0.05$ based on 10,000 permutations. contemporary forces [22]. Not surprisingly, the pattern persisted when only sensitive populations were considered $(r=0.9223, p=0.0372)$. A clear positive relationship was also apparent when only tolerant populations were included in the analysis $(r=0.9443)$, but the trend was not significant $(\mathrm{p}=0.0856)$ (Figure $3 \mathrm{C}$ ). The lack of a significant IBD pattern among DLC-adapted populations could be indicative of local selection (in response to chemical contamination) counteracting the effects of history, demography, migration, and drift, but is more likely a consequence of small sample size. It was hypothesized that if selection is a major force shaping patterns of genetic variation among the sampled killifish populations, a strong correlation between pairwise genetic differences and relative differences in sensitivity to PCB126 should be evident. Additional Mantel tests found no such relationship (data not shown).

\section{Loci under selection}

The number of loci with significant $\mathrm{F}_{\mathrm{ST}}$ values greater than 0.10 , suggesting they are greatly differentiated among populations [36], varied among the four sensitive/tolerant population pairings. Of the four comparisons, the largest number of highly differentiated loci was detected between $\mathrm{BI}$ and NBH (Table 6). Included among these loci were the aryl hydrocarbon receptors (AHR) 1 and 2, cathepsin $\mathrm{Z}$, the cytochrome P450s (CYP 1A and 3A30), and the NADH ubiquinone oxidoreductase MLRQ subunit. Only the CYP1A locus exhibited a consistently high $\mathrm{F}_{\mathrm{ST}}$ value across all population pairs while both AHR genes were highly differentiated in all comparisons except for that between $\mathrm{SH}$ and NWK. While great differences were detected between paired populations at the CYP1A locus, a hierarchical AMOVA did not confirm that those differences are associated with DLC sensitivity (Table 5). In contrast, variation at the AHR2 locus could distinguish DLC-sensitive and tolerant groups (Table 5). 


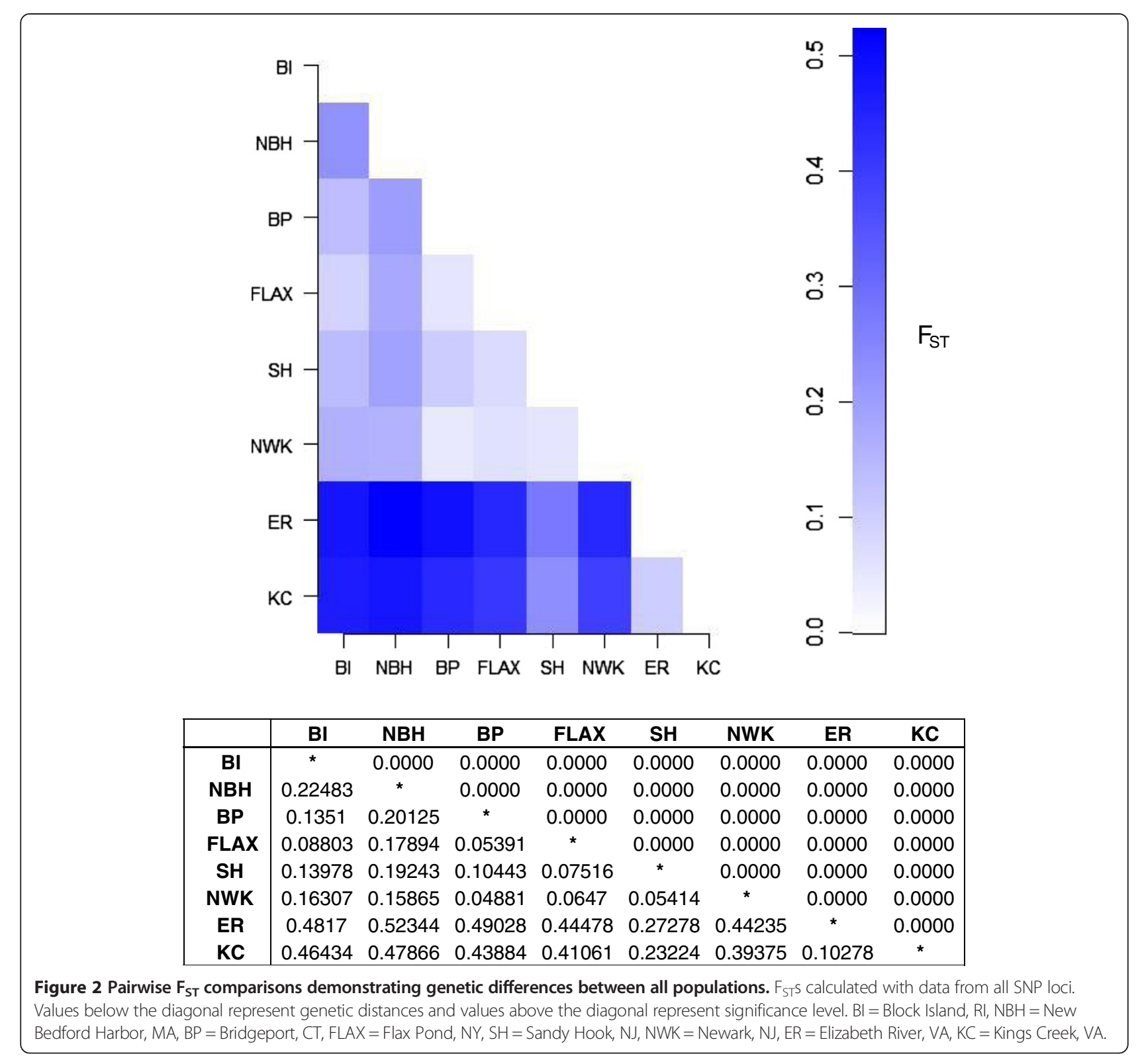

Table 4 T-test results

\begin{tabular}{|c|c|c|c|}
\hline Diversity measure & DLC-sensitive & DLC-tolerant & P-value \\
\hline$P_{0}$ & $0.64(0.07)$ & $0.58(0.07)$ & 0.28 \\
\hline $\mathrm{H}_{\mathrm{O}}$ & $0.15(0.01)$ & $0.14(0.01)$ & 0.23 \\
\hline$H_{E}$ & $0.18(0.03)$ & $0.16(0.01)$ & 0.18 \\
\hline MAF & $0.15(0.02)$ & $0.15(0.01)$ & 1.0 \\
\hline
\end{tabular}

Comparison of mean genetic diversity measures between DLC-sensitive and DLC-tolerant $F$. heteroclitus populations. Standard deviations are in parentheses. $\mathrm{P}_{\mathrm{O}}=$ average percentage of polymorphic loci within groups; $\mathrm{H}_{\mathrm{O}}=$ average observed heterozygosity within groups; $\mathrm{H}_{\mathrm{E}}=$ average expected heterozygosity within groups; $\mathrm{MAF}$ = average minor allele frequency within groups. Results are based on genotype information gathered from 36/37 individuals per population at 59 SNP loci representing 42 genes.
Further exploration of associations between specific loci and DLC sensitivity using an $\mathrm{F}_{\mathrm{ST}}$ modeling approach produced results similar to those derived from the locus-bylocus AMOVA. Again, the CYP1A locus was identified as a significant outlier with respect to the simulated $\mathrm{F}_{\mathrm{ST}}$ null distribution in three out of the four pairwise comparisons between each sensitive population and its DLC-tolerant counterpart. Moreover, when data for all sensitive populations were pooled and compared to the pooled data for all tolerant populations, the AHR2 locus emerged as a significant outlier (Figure 4). These findings lend support to the hypothesis that the CYP1A and AHR2 loci may be involved in the evolution of DLC tolerance.

Evidence of selection can also be gleaned from subtle shifts in allele frequencies in response to environmental 
Table 5 AMOVA results (populations grouped according to DLC sensitivity); data from all loci, CYP1A, and AHR2

\begin{tabular}{|c|c|c|c|c|}
\hline Source of variation & df & $\begin{array}{l}\text { Sum of } \\
\text { squares }\end{array}$ & $\begin{array}{l}\text { Variance } \\
\text { components }\end{array}$ & $\begin{array}{l}\text { Percent } \\
\text { variation }\end{array}$ \\
\hline \multicolumn{5}{|l|}{ All Loci } \\
\hline Among Groups & 1 & 31.573 & $-0.19211\left(V_{a}\right)$ & -4.38 \\
\hline Among Pops w/in Groups & 6 & 528.228 & $1.15127\left(V_{b}\right)$ & 26.27 \\
\hline W/in Pops & 580 & 1985.789 & $3.42377\left(V_{c}\right)$ & 78.12 \\
\hline Total & 587 & 2545.590 & 4.38293 & \\
\hline \multicolumn{5}{|l|}{ CYP1A } \\
\hline Among Groups & 1 & 2.726 & $-0.01613\left(V_{a}\right)$ & -6.52 \\
\hline Among Pops w/in Groups & 6 & 44.501 & $0.09971\left(V_{b}\right)$ & 40.32 \\
\hline W/in Pops & 574 & 93.977 & $0.16372\left(V_{c}\right)$ & 66.20 \\
\hline Total & 581 & 141.204 & 0.24730 & \\
\hline \multicolumn{5}{|l|}{ AHR2 } \\
\hline Among Groups & 1 & 12.822 & $0.03671\left(V_{a}\right)$ & 13.50 \\
\hline Among Pops w/in Groups & 6 & 13.271 & $0.02775\left(V_{b}\right)$ & 10.20 \\
\hline W/in Pops & 570 & 118.296 & $0.20754\left(V_{c}\right)$ & 76.30 \\
\hline Total & 577 & 144.389 & 0.27200 & \\
\hline
\end{tabular}

variables after controlling for population structure [37]. By reviewing differences in minor allele frequency between sensitive and DLC-adapted population pairs, a strong signal was apparent for two SNPs: AHR2_1929 and CYP1A_2140 (Table 7). Upon further examination, the shift in minor allele frequency for the AHR2 SNP varied in magnitude but was consistently in the same direction for all four population comparisons, providing yet another line of evidence linking AHR2 with the DLCtolerant phenotype. This was not the case at the CYP1A locus. Although substantial differences in minor allele frequency were observed between each sensitive and tolerant pair, the frequency shift between $\mathrm{KC}$ and ER was in the direction opposite of the other three pairings (Figure 5).

\section{Discussion}

Four independent DLC-adapted killifish populations were contrasted with neighboring sensitive counterparts in an attempt to reveal genetic loci associated with intra-specific DLC tolerance in the wild. The AHR pathway is known to mediate toxic responses to DLCs in all vertebrates and several studies involving killifish have implicated altered AHR pathway function in eliciting the tolerant phenotype $[29,30,37]$. Therefore, a 'candidate gene scan' approach, focused on components and targets of the AHR and interacting pathways represented among available killifish genetic resources, was applied to gain a better understanding of the genetic basis for the observed phenotypic variation in DLC sensitivity among killifish populations.
Genetic diversity and population structure of tolerant killifish populations were examined with the expectation that patterns of historical stress would be revealed. Levels of genetic diversity and population structure in killifish have been evaluated in several studies; some with the specific aim of addressing the impacts of pollutant-driven selection [9,22,38-41]. Results of the multi-locus analyses conducted here are in agreement with previous reports. Comparably high levels of genetic variation were estimated for all populations, rendering the hypothesis that a genetic bottleneck facilitated the emergence of the DLC-adaptive phenotype highly unlikely. With respect to population structure, each population included in this study was moderately to highly different from all others and observed $\mathrm{F}_{\mathrm{ST}}$ values were comparably higher than earlier measures for killifish populations spanning a similar geographic range (e.g. $\mathrm{F}_{\mathrm{ST}}$ ranged from 0.03 0.2 in [38] and from $0.01-0.24$ in [41]). The difference in the extent of population structure detected among independent studies could be a consequence of the type of markers used (targeted SNPs vs. putatively neutral microsatellites); however, the overall patterns are consistent: genetic differences appear to be driven by geographic distance (latitudinal or shoreline) rather than DLC sensitivity. Moreover, a hierarchical AMOVA did not attribute any of the existing molecular variation to differences between DLC-sensitive and DLC-tolerant groups.

The failure to detect a significant relationship between multi-locus measures of genetic diversity/differentiation and increased tolerance to DLCs may be because a majority of the markers used in the current and previous analyses are selectively neutral. It has been suggested that neutral markers best reflect the effects of anthropogenicallymediated environmental change when populations are in decline and genetic exchange among populations is restricted [42]. There is no evidence that either sensitive or DLC-tolerant killifish populations have experienced a reduction in population size $[22,38,39]$. A more plausible explanation for the rapid adaptation to DLC contamination is that the trait in question is controlled by a small number of loci $[39,43]$. This explanation is consistent with theoretical models that predict single allelic differences of large effect dominate adaptive shifts when environmental change is sudden and selection is intense [42]. The prediction has been tested and verified in insect populations reacting to pesticides [44], benthic marine invertebrates subject to heavy metal toxicity [45], and fish exposed to DLCs [6].

Phenotypic similarities among tolerant populations exposed to a prototypical DLC (e.g. LC20) [2] supported an expectation of common loci under selection; however, genetic loci associated with tolerance might vary across populations due to differences in the selective agents present in their native habitats. The presumed 

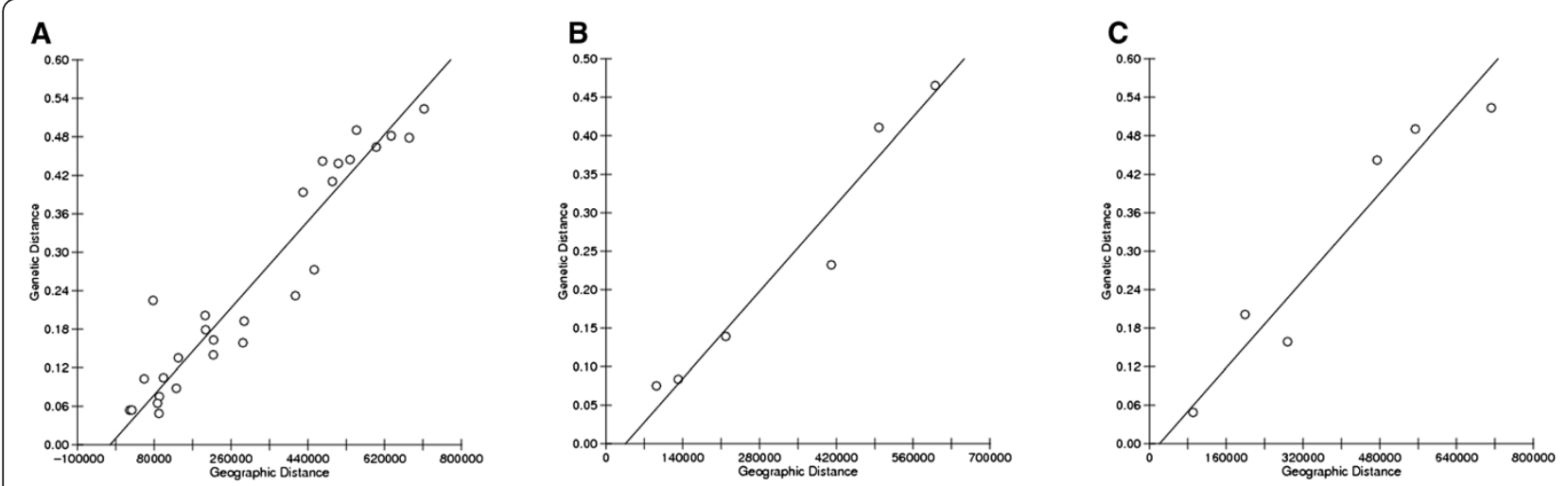

Figure 3 Reduced major axis regression of genetic distance and geographic distance. Genetic distance = pairwise FST; $_{\text {Geographic }}$ (latitudinal) distance in meters. (A) All populations (B) DLC-sensitive populations only (C) DLC-tolerant populations only.

selective agents include large classes of aromatic hydrocarbons whose toxic effects are mediated fully (DLCs) or partly (polycyclic aromatic hydrocarbons, PAHs) through the AHR pathway. While urban contamination includes moderate levels of both PAHs and PCBs, toxic levels of DLCs have been measured at NBH and NWK, PAHs at ER, and both at BP $[2,46]$. Therefore, genetic analyses were conducted to identify common loci under selection in tolerant populations, and differences between sensitive/tolerant paired killifish populations.

Since functional variation in AHR-ligand binding initiates the AHR pathway cascade (and largely explains some intraand inter-species differences in DLC sensitivity, e.g. [15] and references therein), evidence for selection acting on AHR loci was of obvious interest in comparing tolerant versus sensitive killifish populations. As in other fish species, killifish possess at least two distinct $\mathrm{AH}$ receptor genes, AHR1 and AHR2, and the expression of AHR2 predominates in most tissues [47]. Strong signals of selection were detected for an AHR1 (AHR1_1530) and AHR2 SNP (AHR2_1929) included in this analysis in three of the four pairwise comparisons (SH/NWK excluded) when locusby-locus $\mathrm{F}_{\mathrm{ST}}$ were considered. Although these two SNPs are synonymous and do not result in amino acid changes, they are both located in the transactivation domain of their respective AHR genes and in close proximity to nonsynonymous SNPs found to be under selection in Reitzel et al. [9]. Minor allele frequencies (equivalent to base frequencies referred to in [9]) of the AHR2_1929 SNP were consistently higher in the DLC-tolerant populations for all four population pairs. Although the $\mathrm{F}_{\mathrm{ST}}$ modeling approach identified the AHR1_1530 SNP as a significant outlier in only one of the comparisons (BI/NBH), when genotype data from all DLC-sensitive populations were pooled and compared to that of all DLC-tolerant populations AHR2_1929 was the only locus found to deviate from neutral expectations. Similar patterns of genetic variation in AHR1 and AHR2 loci is not surprising given that these two genes are arranged in tandem (and therefore linked) within the killifish genome $[9,48]$. To determine whether variation in both loci, a single locus, or neither locus underlies the DLC-tolerant phenotype, population genetic data must be accompanied by functional assays. A focused examination of allelic variation in killifish AHR1 and AHR2 revealed SNPs under positive selection in both genes; however, AHR1 variants were not responsible for alterations in receptor function and AHR2 variations have yet to be tested $[7,9]$. Studies investigating the genetic basis for DLC-tolerance in zebrafish and Atlantic tomcod have isolated an AHR2 gene as a key player in mediating DLC sensitivity $[6,48]$; while AHR1 and AHR2 seem to play functional roles in dioxin toxicity in red seabream [35]. Taken together, these results suggest that AHR2 variation likely plays a strong role in DLC sensitivity and tolerance in killifish, but more complex interactions may be revealed as new AHR paralogs are being identified and characterized [9].

Consistent with the refractory induction patterns for CYP1A (an early and sensitive marker of AHR pathway activation) observed among DLC-tolerant killifish populations in laboratory studies $[2,29,49]$, the CYP1A SNP emerged as a strong candidate for selection in all tolerant populations. High $\mathrm{F}_{\mathrm{ST}}$ values and large differences in minor allele frequencies were observed at the CYP1A locus in all four population comparisons and the $\mathrm{F}_{\mathrm{ST}}$ modeling approach identified CYP1A as a significant outlier in three out of the four comparisons (BI/NBH excluded). However, the shift in allele frequency, although significant, was not in the same direction across all comparisons. A full genome scan analysis of three of the same tolerant killifish populations (excluding BP) and their sensitive counterparts also identified a SNP marker in the CYP1A promoter region as the only locus (out of 354 screened) under selection in all three DLCtolerant populations surveyed, but again, the direction of the allele frequency shift between DLC-sensitive 
Table 6 Single locus $\mathrm{F}_{\mathrm{ST}}$ values demonstrating high differentiation among population pairs

\begin{tabular}{|c|c|c|c|c|}
\hline \multirow[b]{2}{*}{ Locus } & \multicolumn{4}{|c|}{ Population comparison } \\
\hline & $\mathrm{BI} / \mathrm{NBH}$ & FLAX/BP & SH/NWK & KC/ER \\
\hline Aryl hydrocarbon receptor 1_1530 & 0.48393 & 0.15677 & -0.00349 & 0.12191 \\
\hline Aryl hydrocarbon receptor 1_161 & 0.26498 & 0.00028 & 0.00929 & N/A \\
\hline Aryl hydrocarbon receptor 1_2289 & 0.21749 & N/A & -0.00376 & N/A \\
\hline Aryl hydrocarbon receptor 1_948 & 0.35061 & -0.0137 & -0.01388 & N/A \\
\hline Aryl hydrocarbon receptor 2_1929 & 0.25477 & 0.1825 & 0.04692 & 0.19729 \\
\hline Aryl hydrocarbon receptor 2_792 & 0.36916 & N/A & 0.00417 & N/A \\
\hline Cathepsin F_653 & 0.18941 & -0.0137 & -0.01271 & 0.03401 \\
\hline Cathepsin Z_624 & 0.22978 & 0.04241 & -0.00759 & -0.00325 \\
\hline Cytochrome P450 1A_2140 & 0.37453 & 0.3733 & 0.20304 & 0.70083 \\
\hline Cytochrome P450 3A_1166 & 0.51614 & -0.01332 & -0.00179 & -0.01449 \\
\hline Hepcidin2_399 & 0.14131 & 0.06457 & 0.00719 & 0.04197 \\
\hline Heat shock protein 90_775 & 0.09438 & N/A & 0.02932 & 0.12676 \\
\hline NADH ubiquinone oxidoreductase MLRQ subunit_363 & 0.32115 & -0.01268 & 0.12679 & -0.01516 \\
\hline Myosin regulatory light chain 3_372 & 0.11663 & -0.00843 & -0.01529 & 0.0674 \\
\hline NADH dehydrogenase subunit 4_347 & 0.0137 & N/A & 0.24148 & N/A \\
\hline NADH dehydrogenase subunit 4_586 & 0.01315 & N/A & 0.13504 & 0.01408 \\
\hline NADH dehydrogenase subunit 4_669 & 0.01259 & N/A & 0.25714 & N/A \\
\hline NADH dehydrogenase subunit 6_787 & 0.01486 & N/A & 0.26028 & N/A \\
\hline Serine protease inhibitor_938 & 0.00078 & N/A & 0.03176 & 0.10229 \\
\hline TBT binding protein_635 & 0.10673 & -0.00786 & -0.00228 & N/A \\
\hline Thioredoxin_582 & 0.19931 & 0.01625 & -0.00785 & 0.1248 \\
\hline
\end{tabular}

$\mathrm{F}_{\mathrm{ST}}$ values for highly differentiated loci across all four DLC-sensitive/-tolerant population pairs. $\mathrm{F}_{\mathrm{ST}} \mathrm{s}$ were calculated using the locus by locus AMOVA function in Arlequin v. 3.5. Values exceeding an $\mathrm{F}_{\mathrm{ST}}$ threshold of 0.1 are noted in bold and are significant at $\mathrm{p}<0.05$. Comparisons that were not made because the markers were monomorphic in some populations are noted as N/A. BI = Block Island, NBH = New Bedford Harbor, Flax $=$ Flax Pond, BP $=$ Bridgeport, $\mathrm{SH}=\mathrm{Sandy}$ Hook, $\mathrm{NWK}=$ Newark, $\mathrm{KC}=$ Kings Creek, and $\mathrm{ER}=$ Elizabeth River.

and tolerant populations was not uniform [11]. In a follow-up study, Williams and Oleksiak [50] found that CYP1A promoter variants derived from a DLC-tolerant population $(\mathrm{NBH})$ resulted in elevated expression of CYP1A in vitro, contradicting the well-documented refractory response of CYP1A to DLC exposure among tolerant populations in vivo. These previously reported results, coupled with the knowledge that the CYP1A SNP included in this analysis is located in the 3' untranslated region of the gene [51] make the exact functional role (if any) of CYP1A SNPs in the DLCtolerant phenotype unclear. It may be that additional, yet to be discovered factors associated with CYP1A regulation are also important.

The interpretation of CYP1A as a candidate for selection must also take into account that tolerance has evolved in response to different AHR ligands. Specifically, the role of CYP1A in AHR-mediated toxicity varies by ligand class. Classically described, AHR agonists induce the production of enzymes (predominantly CYP1A) that metabolize PAHs, but not DLCs. Unlike DLC toxicity, PAH toxicity is selflimiting, due to AHR-enhanced PAH elimination, and includes components that are not AHR-mediated. For example, CYP1A knockdown studies in zebrafish embryos have demonstrated the protective value of CYP1A during developmental PAH exposures [52]. That tolerant killifish populations from varied selective environments (PAH- versus DLC-dominated pollution profiles) show similar, poorly-inducible CYP1A phenotypes warrants the consideration of the adaptive value of the CYP1A recalcitrant phenotype more broadly, e.g., as an energy conservation strategy associated with chronic pollution exposures. As in other species [53,54], variation in the CYP1A sequence among killifish populations may be beneficial if associated with conditional fitness under transient, low level PAH exposures. Alternatively, variation in CYP1A may be related to its position 'downstream' in the AHR pathway, and secondary to changes in 'upstream' loci, causally associated with tolerance. Regardless of mechanism, variation at the CYP1A locus differentiates tolerant from sensitive killifish.

Among nearby sensitive/tolerant killifish population comparisons, the $\mathrm{BI} / \mathrm{NBH}$ pairing was the most genetically differentiated based on multi-locus $\mathrm{F}_{\mathrm{ST}}$; many 


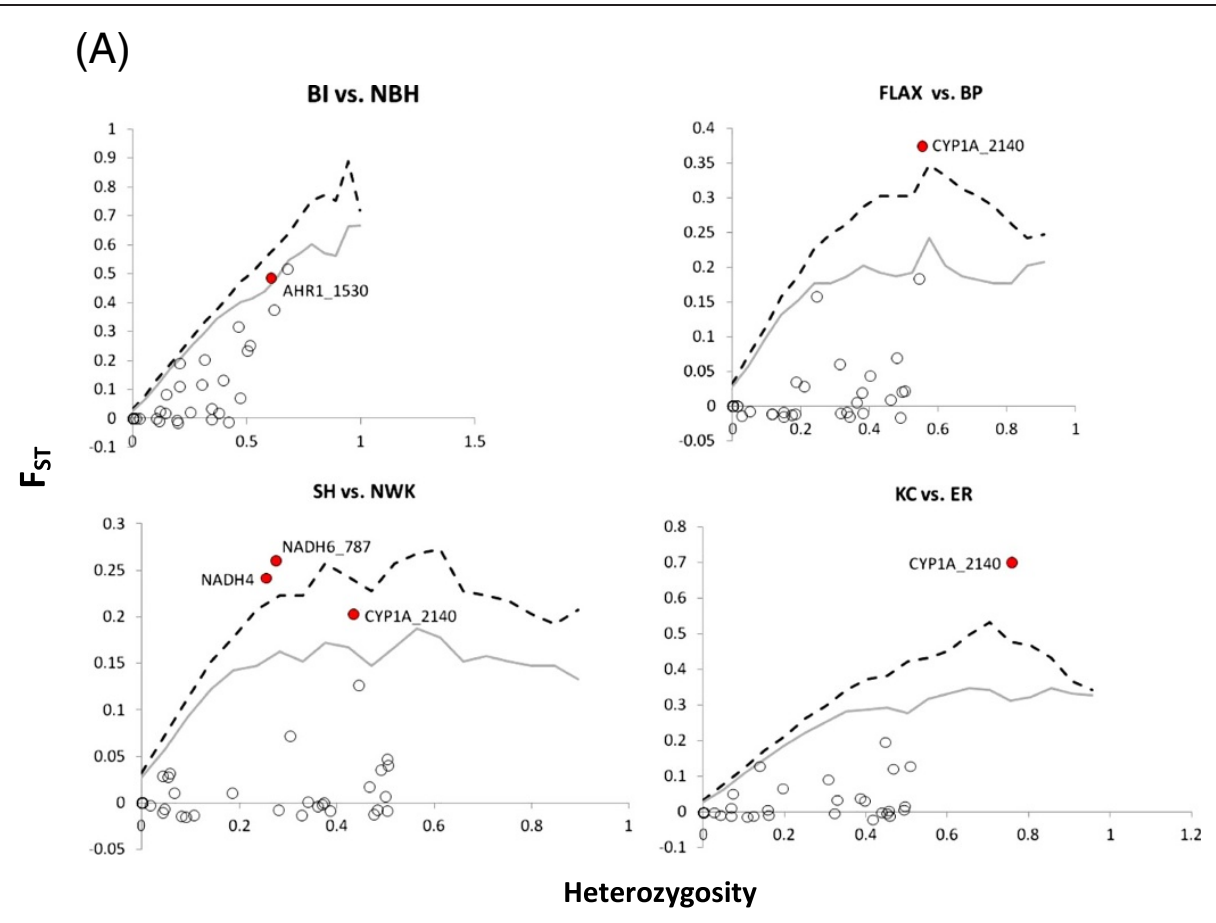

(B)

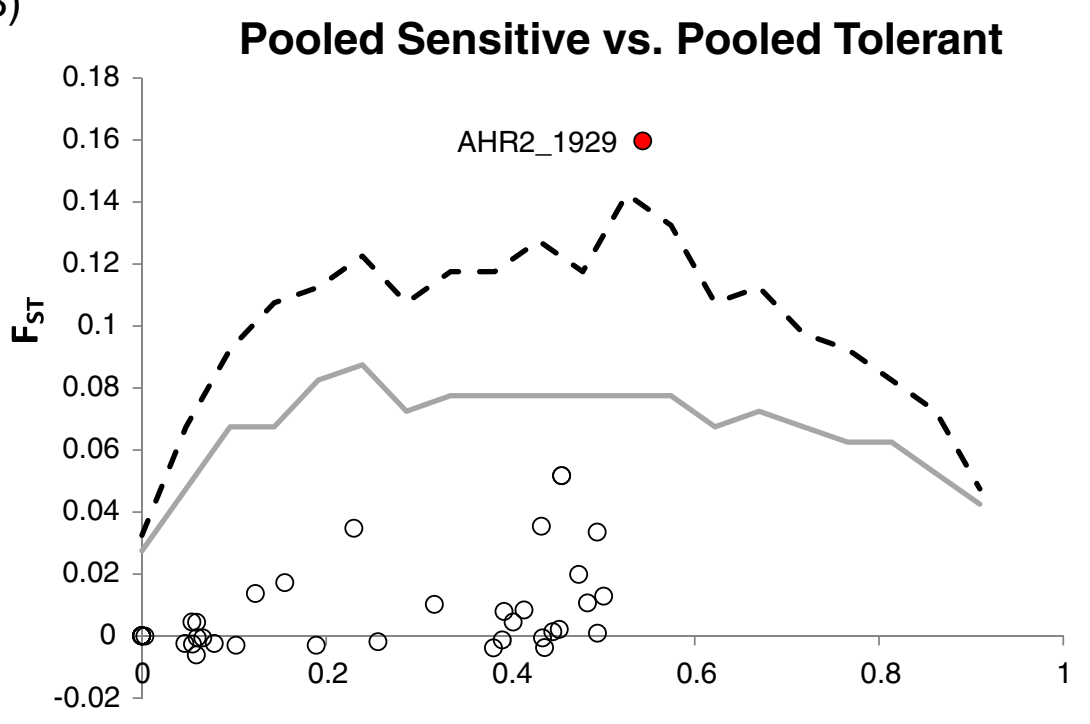

Heterozygosity

Figure 4 Results of an $F_{S T}$ modeling approach to detect loci under selection. Empirical $F_{S T}$ values have been plotted against heterozygosity for each pairing of DLC-sensitive and DLC-tolerant sites (A) and for the pooled DLC-sensitive/-tolerant comparison (B). Gray lines represent the

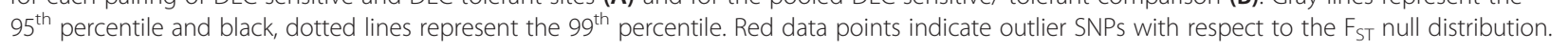

additional loci were identified as candidates for selection (i.e., $\mathrm{F}_{\mathrm{ST}}>0.1$ and significant allele frequency shifts). In addition to the AHRs and CYP1A, these populations appear to be highly differentiated at cathepsin $F$, cathepsin $\mathrm{Z}$, CYP3A30, and the NADH ubiquinone oxidoreductase MLRQ subunit loci. Cathepsins are a large group of proteolytic enzymes that have been implicated in cardiomyopathies and cardiovascular disease, ultimately resulting in impaired pump function [55,56]. Given that the cardiovascular system is a main target of DLC toxicity in all vertebrates [48], it is reasonable to propose that alterations in the cathepsin coding sequence could contribute to existing differences in DLC sensitivity. CYP3A30 is an abundant xenobiotic metabolizing enzyme in killifish livers responsible for the breakdown and 
Table 7 Minor allele frequencies of $F$. heteroclitus SNP markers calculated for each population

\begin{tabular}{|c|c|c|c|c|c|c|c|c|c|}
\hline \multirow[b]{2}{*}{ Locus } & \multirow[b]{2}{*}{ Minor allele } & \multicolumn{8}{|c|}{ Population } \\
\hline & & $\mathrm{BI}$ & NBH & FLAX & BP & $\mathrm{SH}$ & NWK & KC & ER \\
\hline Aglobin_89 & $\mathrm{A} / \mathbf{G}$ & 0 & 0 & 0 & 0 & 0 & 0 & 0 & 0 \\
\hline AHR1_1530 & $\mathrm{C} / \mathbf{G}$ & 0.08 & 0.62 & 0.23 & 0.03 & 0.26 & 0.2 & 0.44 & 0.19 \\
\hline AHR1_161 & $\mathrm{C} / \mathbf{G}$ & 0.14 & 0.5 & 0.04 & 0.01 & 0.03 & 0.08 & 0 & 0 \\
\hline AHR1_2289 & $\mathrm{G} / \mathrm{T}$ & 0.07 & 0.64 & 0 & 0 & 0.03 & 0.05 & 0 & 0 \\
\hline AHR1_948 & $\mathrm{C} / \mathrm{T}$ & 0.07 & 0.49 & 0.01 & 0.01 & 0.03 & 0.03 & 0 & 0 \\
\hline AHR2_1929 & $\mathrm{C} / \mathrm{T}$ & 0.15 & 0.51 & 0.27 & 0.59 & 0.49 & 0.67 & 0.57 & 0.87 \\
\hline AHR2_792 & $\mathrm{C} / \mathrm{T}$ & 0.07 & 0.5 & 0 & 0 & 0.03 & 0.07 & 0 & 0 \\
\hline AHR2B_992 & $\mathrm{A} / \mathrm{G}$ & 0 & 0 & 0.05 & 0.07 & 0.05 & 0.01 & 0 & 0 \\
\hline AHRR_1095 & $\mathrm{C} / \mathrm{T}$ & 0 & 0 & 0.11 & 0.05 & 0 & 0 & 0 & 0.06 \\
\hline AHRR_1299 & $C / T$ & 0 & 0 & 0.15 & 0.05 & 0 & 0 & 0.01 & 0.06 \\
\hline ANP_521 & $C / T$ & 0.24 & 0.44 & 0.7 & 0.41 & 0.29 & 0.23 & 0.38 & 0.28 \\
\hline BAD_213 & $\mathrm{G} / \mathrm{T}$ & 0.15 & 0.28 & 0.24 & 0.27 & 0.21 & 0.28 & 0.06 & 0.07 \\
\hline Bglobin_193 & $C / T$ & 0 & 0 & 0 & 0.01 & 0.03 & 0.01 & 0.1 & 0.07 \\
\hline Cardiac_MLC1_250 & $\mathrm{C} / \mathrm{T}$ & 0 & 0 & 0 & 0 & 0 & 0 & 0 & 0 \\
\hline CathE_730 & $\mathrm{A} / \mathrm{C}$ & 0 & 0 & 0 & 0 & 0 & 0 & 0 & 0 \\
\hline CathF_653 & $\mathrm{A} / \mathbf{T}$ & 0.2 & 0 & 0.09 & 0.09 & 0.21 & 0.2 & 0.14 & 0.26 \\
\hline CathZ_624 & $\mathrm{G} / \mathrm{T}$ & 0.5 & 0.15 & 0.19 & 0.34 & 0.43 & 0.38 & 0.31 & 0.38 \\
\hline CC3_571 & $A / \mathbf{G}$ & 0 & 0 & 0 & 0 & 0 & 0 & 0 & 0 \\
\hline CYP1A_2140 & $\mathrm{A} / \mathrm{T}$ & 0.73 & 0.24 & 0.57 & 0.11 & 0.42 & 0.11 & 0.2 & 0.93 \\
\hline CYP3A_1166 & $\mathrm{A} / \mathrm{G}$ & 0.78 & 0.19 & 0.42 & 0.43 & 0.21 & 0.28 & 0.06 & 0.06 \\
\hline CytB5_626 & $\mathbf{G} / \top$ & 0.01 & 0 & 0.01 & 0.01 & 0.06 & 0.05 & 0.07 & 0 \\
\hline ERa_1497 & $\mathbf{G} / \top$ & 0 & 0 & 0 & 0 & 0 & 0 & 0 & 0 \\
\hline ERba_1373 & $\mathrm{C} / \mathrm{T}$ & 0.19 & 0.25 & 0.51 & 0.38 & 0.68 & 0.47 & 0.04 & 0.03 \\
\hline GP3D_530 & $\mathbf{A} / \mathrm{G}$ & 0 & 0 & 0 & 0.01 & 0 & 0 & 0 & 0 \\
\hline Hepcidin_69 & $\mathrm{C} / \mathrm{T}$ & 0.11 & 0.08 & 0.07 & 0.16 & 0.01 & 0.03 & 0 & 0 \\
\hline Hepcidin2_399 & $\mathrm{A} / \mathbf{G}$ & 0.12 & 0.37 & 0.26 & 0.11 & 0.39 & 0.49 & 0.68 & 0.82 \\
\hline HSP90_775 & $A / \mathbf{G}$ & 0.01 & 0.14 & 0 & 0 & 0.04 & 0 & 0.14 & 0 \\
\hline Kallikrein_502 & $\mathrm{G} / \mathrm{T}$ & 0 & 0 & 0 & 0 & 0 & 0 & 0 & 0 \\
\hline KallikreinS_309 & $\mathrm{A} / \mathbf{G}$ & 0 & 0 & 0 & 0 & 0 & 0 & 0 & 0 \\
\hline MLC2_436 & $\mathrm{C} / \mathrm{T}$ & 0 & 0 & 0.07 & 0.05 & 0.14 & 0.07 & 0.19 & 0.33 \\
\hline MLC2_535 & $\mathrm{A} / \mathrm{C}$ & 0 & 0 & 0.03 & 0.01 & 0.07 & 0 & 0.32 & 0.35 \\
\hline MLCA_577 & $\mathrm{C} / \mathrm{T}$ & 0.09 & 0.03 & 0.08 & 0.08 & 0.26 & 0.09 & 0.03 & 0.01 \\
\hline MLRQ_363 & $\mathrm{A} / \mathrm{T}$ & 0.46 & 0.07 & 0.11 & 0.09 & 0.42 & 0.17 & 0.7 & 0.7 \\
\hline MRCL3_372 & $\mathrm{A} / \mathrm{G}$ & 0.27 & 0.14 & 0.22 & 0.18 & 0.05 & 0.04 & 0.17 & 0.04 \\
\hline NADH10_107 & $A / T$ & 0.19 & 0.03 & 0.15 & 0.24 & 0.14 & 0.05 & 0.13 & 0.31 \\
\hline NADH10_439 & $\mathrm{C} / \mathrm{T}$ & 0.31 & 0.28 & 0.23 & 0.19 & 0.25 & 0.18 & 0.51 & 0.64 \\
\hline NADH2_349 & $\mathbf{A} / \mathrm{G}$ & 0 & 0 & 0.11 & 0.05 & 0 & 0.05 & 0.03 & 0 \\
\hline NADH3_165 & $\mathrm{C} / \mathbf{G}$ & 0 & 0 & 0 & 0 & 0 & 0 & 0 & 0 \\
\hline NADH4_347 & $\mathrm{C} / \mathrm{T}$ & 0.03 & 0 & 0 & 0 & 0.26 & 0 & 1 & 1 \\
\hline NADH4_586 & $\mathrm{A} / \mathbf{G}$ & 0.03 & 0 & 0 & 0 & 0.27 & 0.05 & 0.03 & 0 \\
\hline NADH4_669 & $\mathrm{G} / \mathrm{T}$ & 0.03 & 0 & 0 & 0 & 0.28 & 0 & 1 & 1 \\
\hline NADH6_787 & $\mathrm{A} / \mathrm{G}$ & 0.08 & 0.05 & 0 & 0 & 0.28 & 0 & 1 & 1 \\
\hline PCFXI_511 & $\mathbf{G} / \top$ & 0 & 0 & 0 & 0 & 0 & 0 & 0 & 0 \\
\hline
\end{tabular}


Table 7 Minor allele frequencies of $\boldsymbol{F}$. heteroclitus SNP markers calculated for each population (Continued)

\begin{tabular}{|c|c|c|c|c|c|c|c|c|c|}
\hline RARR1_759 & $\mathrm{A} / \mathrm{C}$ & 0.08 & 0.14 & 0.22 & 0.21 & 0.52 & 0.35 & 0.7 & 0.39 \\
\hline RGST_397 & $\mathrm{A} / \mathbf{T}$ & 0.1 & 0.12 & 0.19 & 0.3 & 0.14 & 0.19 & 0.52 & 0.64 \\
\hline SPI_938 & $\mathbf{A} / \mathrm{G}$ & 0.04 & 0.08 & 0 & 0 & 0.06 & 0 & 0.27 & 0.08 \\
\hline TBTbp_635 & $\mathbf{A} / \top$ & 0.03 & 0.18 & 0.04 & 0.02 & 0.02 & 0 & 0 & 0 \\
\hline Thioredoxin_582 & A/G & 0.3 & 0.04 & 0.53 & 0.65 & 0.47 & 0.5 & 0.75 & 0.49 \\
\hline TIF2_727 & $\mathrm{C} / \mathrm{T}$ & 0 & 0 & 0 & 0 & 0.04 & 0.04 & 0.11 & 0.06 \\
\hline Titin_478 & $\mathrm{C} / \mathrm{G}$ & 0.19 & 0.1 & 0.46 & 0.26 & 0.42 & 0.3 & 0.66 & 0.64 \\
\hline TroponinT2_653 & $\mathrm{C} / \mathrm{T}$ & 0.3 & 0.19 & 0.28 & 0.19 & 0.38 & 0.4 & 0.17 & 0.23 \\
\hline
\end{tabular}

Zero values indicate populations where the SNP marker was monomorphic. Minor alleles in bold.

clearance of a wide array of anthropogenically derived pollutants [57] and has been identified as a target of the AHR pathway [58]. In killifish, expression of this gene was found to be significantly higher in field caught ER females relative to those collected from $\mathrm{KC}$ [31]; however, it was not differentially expressed in killifish embryos derived from the same DLC-tolerant and sensitive populations included in this study when exposed to PCB126 under controlled laboratory conditions [29,37]. Mutations in the NADH ubiquinone oxidoreductase MLRQ subunit are associated with metabolic diseases [28]. Again, expression of this gene was found to be significantly higher in field caught ER females relative to those collected from $\mathrm{KC}$ [31]. Moreover, expression of another component of the NADH ubiquinone oxidoreductase enzyme, NDUB2, was found to be higher in the brains of $\mathrm{NBH}, \mathrm{NWK}$, and ER adult fish [59]. The repeated association of $\mathrm{NADH}$ ubiquinone oxidoreductase with DLCtolerance suggests that biochemical pathways other than the AHR could be involved in this chemically-induced stress response.

It is not known whether the identification of additional candidate loci for strong selection in the $\mathrm{BI} / \mathrm{NBH}$ pair only suggests unique tolerance-related or biologically-relevant differences (BI is the only oceanic rather than estuarine site
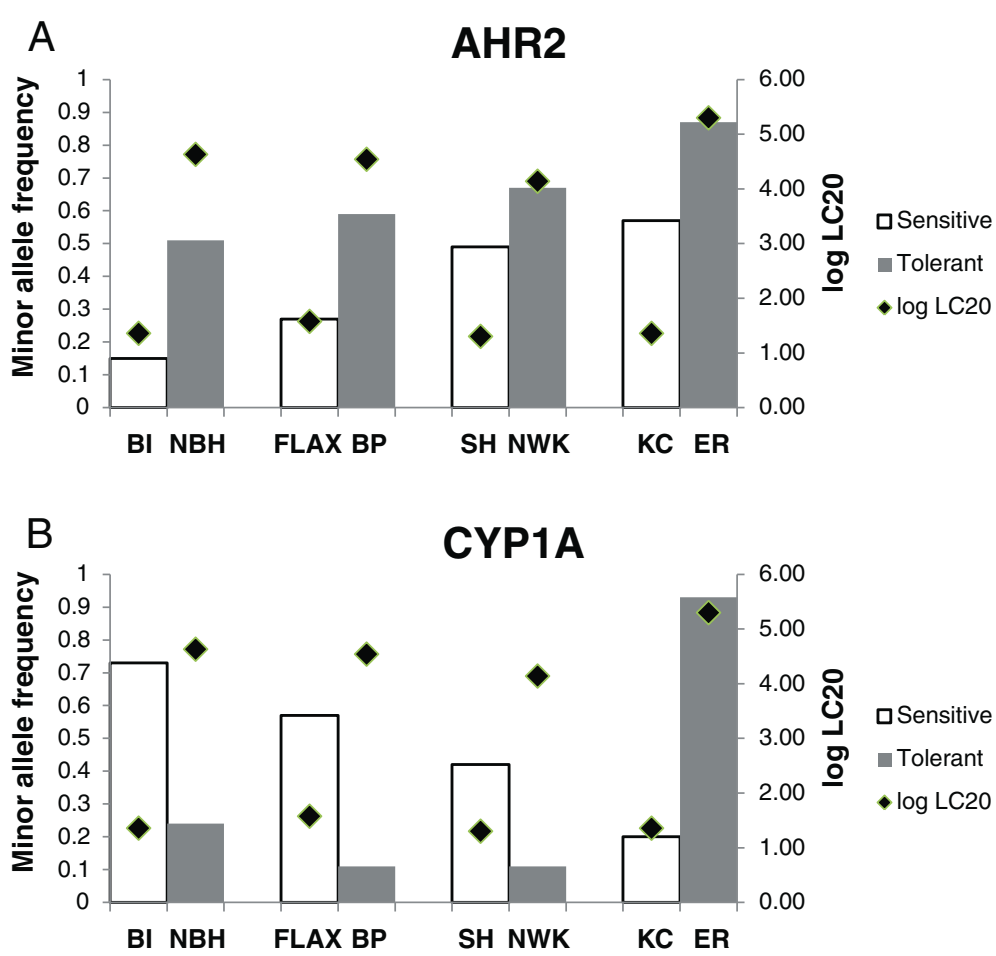

Figure 5 Shifts in minor allele frequencies across populations for (A) AHR2 and (B) CYP1A. Populations are arranged with respect to geographical region. Corresponding log LC20 values measured in response to PCB126 for each population (Nacci et al. 2010) are also noted. 
included in this analysis) or technical artifacts (statistical power). While similar phenotypes among the four tolerant populations examined suggest a conserved biochemical basis for intra-specific DLC tolerance in killifish, whether that similarity is constrained to identical nucleotide changes remains to be seen. The genetic mechanisms of adaptation could vary among DLC-tolerant populations. Alternatively, the differences detected may be a reflection of additional unique stressors encountered by each population pair.

\section{Conclusions}

The purpose of this study was to identify genetic polymorphisms associated with DLC sensitivity in Atlantic killifish from a suite of candidate loci involved in the AHR and interacting pathways; whether the polymorphisms in and of themselves are responsible for the drastic differences in DLC sensitivity among populations was beyond the scope of this work. Two loci, AHR2 and CYP1A, displayed patterns of variation consistent with selection in each of four pairwise comparisons. Additional loci with specific alleles significantly overrepresented in some, but not all, DLC tolerant populations underscore the possibility that the genetic variation in each population may have been shaped by similar yet unique selection pressures. Although the intention was to include all components of the AHR and interacting pathways in this population screen, the underrepresentation or absence of key genes (e.g., aryl hydrocarbon receptor nuclear translocator (ARNT)) in the $F$. heteroclitus unigene database resulted in an enriched but incomplete set of candidate genetic markers for DLC toxicity and (presumably) tolerance. Genetic resources being made available through the Fundulus genome consortium as well as a parallel, unbiased, Quantitative Trait Locus (QTL) approach to the discovery of the genetic mechanism of DLC tolerance in killifish will greatly increase our understanding of this dramatic example of anthropogenically induced, rapid adaptation in the wild.

\section{Availability of supporting data}

The sequences for the SNPs analyzed in this article are available through the Dryad Digital Depository and can be accessed by searching for the data package title Data from: Targeted approach to identify genetic loci associated with evolved dioxin tolerance in Atlantic Killifish (Fundulus heteroclitus), doi:10.5061/dryad.2355t Data files: Proestou_etal_Killifish_SNP_sequences.

\section{Additional file}

Additional file 1: List of all genes considered for SNP analysis and their fate during the marker development process. Sequences provided by Sibel Karchner were derived from either 26 (AHR1, AHR2, and AHRR) or 10 individuals (not CDNA libraries) collected from Scorton Creek, MA. In some cases, Qualitiy SNP identified multiple available contigs from a single unigene entry. The number of SNPs genotyped does not equal the number of SNPs in the analysis because 8 of the markers failed to provide quality genotype information. $\mathrm{N}=\mathrm{No}, \mathrm{Y}=\mathrm{Yes}$, $\mathrm{N} / \mathrm{A}=$ Not available, $\mathrm{U}=$ Unknown.

\section{Abbreviations}

DLC: Dioxin-like compound; AHR: Aryl hydrocarbon receptor;

PCB: Polychlorinated biphenyl; PAH: Polycyclic aromatic hydrocarbon; BI: Block Island; NBH: New bedford harbor; BP: Bridgeport; FLAX: Flax pond; SH: Sandy hook; NWK: Newark; ER: Elizabeth river; KC: Kings creek.

\section{Competing interests}

The authors declare they have no competing interests.

\section{Authors' contributions}

DAP, PF, DC, and DN contributed to study design, sample collection and processing. DP performed data analysis. DP and DN wrote the manuscript. All authors read and approved the final manuscript.

\section{Acknowledgements}

We owe many thanks to M. Hahn, S. Karchner, and D. Franks for sharing unpublished sequence and SNP data and for useful discussions. Helpful discussions with Eric Waits, technical support from Jason Grear, John Martinson, Mike Charpentier, lan Kirby, Ashley Bertrand, and James Heltshe, and the advice from reviewers of earlier drafts, Mark Hahn, Sibel Karchner, Jeffrey Markert, John Martinson, Anne Kuhn, and 3 anonymous reviewers are also much appreciated. This is ORD tracking number ORD-005088 of the U.S. Environmental Protection Agency, Office of Research and Development, National Health and Environmental Effects Research Laboratory, Atlantic Ecology Division. This manuscript has been reviewed and approved for publication by the U.S. EPA. Approval does not signify that the contents necessarily reflect the views and policies of the U.S EPA. Mention of trade names, products, or services does not convey, and should not be interpreted as conveying official U.S. EPA approval, endorsement, or recommendation.

\section{Author details}

'US Environmental Protection Agency, Office of Research and Development, National Health and Environmental Effects Research Laboratory, Atlantic Ecology Division, 27 Tarzwell Drive, Narragansett, RI 02882, USA. ²Department of Ecology and Evolutionary Biology, Brown University, 80 Waterman Street, Providence, RI 02912, USA. ${ }^{3}$ Current address: USDA Agricultural Research Service, 469 Center for Biotechnology and Life Sciences, 120 Flagg Road, Kingston, RI 02881, USA.

Received: 7 August 2013 Accepted: 30 December 2013 Published: 14 January 2014

\section{References}

1. Van Veld PA, Nacci D: Chemical tolerance: Aclimation and adaptations to chemical stress. In The Toxicology of Fishes. Edited by Diguilio RT, Hinton DE. Washington, DC: Taylor \& Francis; 2008:597-644.

2. Nacci DE, Champlin D, Jayaraman S: Adaptation of the Estuarine Fish Fundulus heteroclitus (Atlantic Killifish) to Polychlorinated Biphenyls (PCBs). Estuaries Coast 2010, 33:853-864.

3. Pohjanvirta R, Korkalainen M, Moffat ID, Boutros PC, Okey AB: Role of the AHR and its structure in TCDD toxicity. In The AH Receptor in Biology and Toxicology. 1st edition. Edited by Pohjanvirta R. New Jersey: John Wiley \& Sons; 2012:181-196.

4. Head JA, Hahn ME, Kennedy SW: Key amino acids in the aryl hydrocarbon receptor predict dioxin sensitivity in avian species. Environ Sci Technol 2008, 42:7535-7541.

5. Farmahin R, Manning GE, Crump D, Wu D, Lukas JM, Jones SP, Hahn ME, Karchner SI, Giesy JP, Bursian SJ, Zwiernik SJ, Frederick TB, Kennedy SW: Amino acid sequence of the ligand-binding domain of the aryl hydrocarbon receptor 1 predicts sensitivity of wild birds to effects of dioxin-like compounds. Toxicol Sci 2013, 131:139-152.

6. Wirgin I, Roy NK, Loftus M, Chambers RC, Franks DG, Hahn ME: Mechanistic basis of resistance to PCBs in Atlantic tomcod from the Hudson river. Science 2011, 331:1322-1325. 
7. Hahn ME, Karchner SI, Franks DG, Merson RR: Aryl hydrocarbon receptor polymorphisms and dioxin resistance in Atlantic killifish (Fundulus heteroclitus). Pharmacogenetics 2004, 14:1-13.

8. Hahn ME, Karchner SI, Franks DG, Evans BR, Nacci D, Champlin D, Cohen S: Mechanism of PCB-and Dioxin-Resistance in Fish in the Hudson River Estuary: Role of Receptor Polymorphisms. Final Report, Hudson River Foundation Grant. Final Report, Hudson River Foundation Grant 004/02A http://hudsonriver.org/ls/ 2005.

9. Reitzel AM, Karchner SI, Franks DG, Evans BR, Nacci D, Champlin D, Vieira VM, Hahn M: Genetic diversity at aryl hydrocarbon receptor loci in PCB sensitive and PCB resistant populations of Atlantic killifish (Fundulus heteroclitus). BMC Evol Biol 2014, 14:6.

10. Williams LM, Oleksiak MF: Signatures of selection in natural populations adapted to chronic pollution. BMC Evol Biol 2008, 8:282

11. Williams LM, Oleksiak MF: Ecologically and evolutionarily important SNPs identified in natural populations. Mol Biol Evol 2011, 28:1817-1826.

12. Rosenblum EB, Hoekstra HE, Nachman MW: Adaptive reptile color variation and the evolution of the MCIR gene. Evolution 2004, 58:1794-1808.

13. Jaquiery J, Stoeckal S, Nouhaud P, Mieuzet L, Mahéo F, Legeai F, Bernard N Bonvoisin A, Vitalis R, Simon JC: Genome scans reveal candidate regions involved in the adaptation to host plant in the pea aphid complex. Mol Ecol 2012, 21:5251-5264.

14. Hemmer-Hansen J, Nielsen EE, Meldrup D, Mittelholzer C: Identification of single nucleotide polymorphisms in candidate genes for growth and reproduction in a nonmodel organism; the Atlantic cod Gadus morhua. Mol Ecol Resour 2011, 11(Suppl. 1):71-80.

15. Denison MS, Soshilov AA, He G, DeGroot DE, Zhao B: Exactly the same but different: promiscuity and diversity in the molecular mechanisms of action of the Aryl Hydrocarbon (Dioxin) Receptor. Toxico/ Sci 2011, 124:1-22.

16. Tang J, Vosman B, Voorrips RE, van der Linden CG, Leunissen JAM: QualitySNP: a pipeline for detecting single nucleotide polymorphisms and insertions/deletions in EST data from diploid and polyploid species BMC Bioinforma 2006, 7:438.

17. Wang J, Chuang K, Ahluwalia M, Patel S, Umblas N, Mirel D, Higuchi R, Germer S: High-throughput SNP genotyping by single-tube PCR with Tm-shift primers. Biotechniques 2005, 39:885-892.

18. Nacci D, Coiro L, Champlin D, Jayaraman S, McKinney R, Gleason TR, Munns WR Jr, Specker JL, Cooper KR: Adaptations of wild populations of the estuarine fish Fundulus heteroclitus to persistent environmental contaminants. Mar Biol 1999, 134:9-17.

19. Nacci DE, Champlin D, Coiro L, McKinney R, Jayaraman S: Predicting the occurrence of genetic adaptation to dioxin-like compounds in populations of the estuarine fish Fundulus heteroclitus. Environ Toxicol Chem 2002, 21:1525-1532.

20. Excoffier $L$, Lischer HEL: Arlequin suite ver 3.5: a new series of programs to perform population genetics analysis under Linux and Windows. Mol Ecol Resour 2010, 10:564-567.

21. Wright S: Isolation by distance. Genetics 1943, 28:114-138.

22. Duvernell DD, Lindmeier JB, Faust KE, Whitehead A: Relative influences of historical and contemporary forces shaping the distribution of genetic variation in the Atlantic killifish, Fundulus heteroclitus. Mol Ecol 2008, 17:1344-1360

23. Jensen JL, Bohonak AJ, Kelley ST: Isolation by distance, web service. BMC Genet 2005, 6:13.

24. Beaumont MA, Nichols RA: Evaluating loci for use in the genetic analysis of population structure. Proc R Soc Lond B Biol Sci 1996, 263:1619-1626.

25. Karchner SI, Franks DG, Powell WH, Hahn ME: Regulatory interactions among three members of the vertebrate aryl hydrocarbon receptor family: AHR repressor, AHR1 and AHR2. J Biol Chem 2002, 277:6949-6959

26. Carlson EA, Roy NK, Wirgin II: Microarray analysis of polychlorinated biphenol mixture-induced changes in gene epression among Atlantic tom cod populations displaying differential sensitivity to halogenated aromatic hydrocarbons. Environ Toxicol 2009, 28:759-771.

27. Sartor MA, Schnekenburger M, Marlowe JL, Reichard JF, Wang Y, Fan $Y$, Ma C, Karyala S, Halbleib D, Liu X, Medvedovic M, Puga A: Genomewide analysis of aryl hydrocarbon receptor binding targets reveals an extensive array of gene clusters that control morphogenic and developmental programs. Environ Health Perspect 2009, 117:1139-1146.

28. Meyer JN, Volz DC, Freedman JF, DiGiulio RT: Differential display of hepatic mRNA from Fundulus heteroclitus inhabiting a superfund estuary. Aquat Toxicol 2005, 73:327-341
29. Whitehead A, Triant DA, Champlin D, Nacci D: Comparative transcriptomics implicates mechanisms of evolved pollution tolerance in a killifish population. Mol Ecol 2010, 19:5186-5203.

30. Whitehead A, Pilcher W, Champlin D, Nacci D: Common mechanism underlies repeated evolution of extreme pollution tolerance. Proc $R$ SoC Lond B Biol Sci 2012, 279:427-433.

31. Carney SA, Chen J, Burns CJ, Xiong KM, Peterson RE, Heideman W: Aryl hydrocarbon receptor activation produces heart-specific transcriptional and toxic responses in developing zebrafish. Mol Pharmacol 2006, 70:549-561.

32. Greytak SR, Calllard GV: Cloning of three estrogen receptors (ER) from killifish (Fundulus heteroclitus): differences in populations from polluted and reference environments. Gen Comp Endocrinol 2007 150:174-188.

33. Fisher MA, Oleksiak MF: Convergence and divergence in gene expression among natural populations exposed to pollution. BMC Genomics 2007, 8:108.

34. Paetzold SC, Ross NW, Richards RC, Jones M, Hellou J, Bard SM: Up-regulation of hepatic $A B C C 2, A B C G 2, C Y P 1 A 1$, and GST in multixenobiotic-resistant killifish (fundulus heteroclitus) from the Sydney Tar ponds, nova Scotia, Canada. Mar Environ Res 2009, 68:37-47.

35. Waits ER, Nebert DW: Genetic architecture of susceptibility to PCB-126 induced developmental cardiotoxicity in zebrafish. Toxicol Sci 2011, 122:466-475.

36. Wright S: Evolution and the genetics of populations. Variability within and among natural populations. Vol. 4. Chicago: University of Chicago Press; 1978.

37. Hancock AM, Alkorta-Aranburu G, Witonsky DB, Di Rienzo A: Adaptations to new environments in humans: the role of subtle allele frequency shifts. Philos Trans R Soc Lond B Biol Sci 2010, 365:2459-2468.

38. Roark SA, Nacci D, Coiro L, Champlin D, Guttman SI: Population genetic structure of a nonmigratory estuarine fish (Fundulus heteroclitus) across a strong gradient of polychlorinated biphenyl contamination. Environ Toxicol and Chem 2005, 24:717-725.

39. Adams SM, Lindmeier JB, Duvernell DD: Microsatellite analysis of the phylogeography, Pleistocene history and secondary contact hypotheses for the killifish, fundulus heteroclitus. Mol Ecol 2006, 15:1109-1123.

40. McMillan AM, Bagley MJ, Jackson SA, Nacci DE: Genetic diversity and structure of an estuarine fish (Fundulus heteroclitus) indigenous to sites associated with a highly contaminated urban harbor. Ecotoxicology 2006, 15:539-548.

41. Williams LM, Ma X, Boyko AR, Bustamante CD, Oleksiak MF: SNP identification, verification and utility for population genetics in a non-model genus. BMC Genet 2010, 11:32.

42. Whitehead A, Crawford DL: Neutral and adaptive variation in gene expression. Proc Natl Acad Sci U S A 2006, 103:5425-5430.

43. Oleksiak MF, Karchner SI, Jenny MJ, Franks DG, Welch DBM, Hahn ME: Transcriptomic assessment of resistance to effects of an aryl hydrocarbon receptor (AHR) agonist in embryos of Atlantic killifish (Fundulus heteroclitus) from a marine superfund site. BMC Genomics 2011, 12:263.

44. Hoffmann AA, Willi Y: Detecting genetic responses to environmental change. Nat Rev Genet 2008, 9:421-432.

45. Gahan L, Gould F, Heckel DG: Identification of a gene associated with Bt resistance in Heliothis virescens. Science 2001, 293:857-860.

46. Martinez DE, Levinton J: Adaptation to heavy metals in the aquatic oligochaete Limnodrilus hoffmeisteri: evidence for control by one gene. Evolution 1996, 50:1339-1343.

47. Meyer JN, Di Giulio RT: Heritable adaptation and associated fitness costs in killifish (Fundulus heteroclitus) inhabiting a contaminated estuary. Ecol App/ 2003, 13:490-503.

48. Hahn ME, Karchner SI, Evans BR, Franks DG, Merson RR, Lapseritis JM: Unexpected diversity of aryl hydrocarbon receptors in non-mammalian vertebrates: Insights from comparative genomics. J Exp Zool A Ecol Genet Physiol 2006, 305A:693-706.

49. Bak S-M, lilda M, Hirano M, Iwato H, Kim E-Y: Potencies of Red seabream AHR1- and AHR2-mediated transactivation by dioxins: implicationsof both AHRs in dioxin toxicity. Environ Sci Technol 2013, 47:2877-2885.

50. Mandel PK: Dioxin: a review of its environmental effects and its aryl hydrocarbon receptor biology. J Comp Physiol B Biochem Syst EnvironPhysiol 2005, 175:221-230.

51. Williams LM, Oleksiak MF: Evolutionary and functional analyses of cytochrome P4501A promoter polymorphisms in natural populations. Mol Ecol 2011, 20:5236-5247.

52. Morrison HG, Weil EJ, Karchner SI, Sogin ML, Stegeman JJ: Molecular cloning of CYP1A from the estuarine fish Fundulus heteroclitus and 
phylogenetic analysis of CYP1 genes: update with new sequences. Comp Biochem Physiol Part C Toxicol Pharmacol 1998, 121:231-240.

53. Billiard SM, Timme-Laragy AR, Wessenberg DM, Cockman C, Di Giulio RT: The role of the aryl hydrocarbon receptor pathway in mediating synergistic developmental toxicity of polycyclic aromatic hydrocarbons to zebrafish. Toxicol Sci 2006, 92:526-536.

54. Goldstone H, Stegeman J: A revised evolutionary history of the CYP1A subfamily: gene duplication, gene conversion and positive selection. $J \mathrm{Mol}$ Evol 2006, 62:708-717.

55. Zhou H, Qu Y, Wu H, Liao C, Zheng J, Diao X, Xue Q: Molecular phylogenies and evolutionary behavior of AhR (aryl hydrocarbon receptor) pathway genes in aquatic animals: implications for the toxicology mechanism of some persistent pollutants (POPs). Chemosphere 2010, 87:193-205.

56. Lutgens SPM, Cleutjens KBJM, Daemen MJAP, Heeneman S: Cathepsin cysteine proteases in cardiovascular disease. FASEB J 2007, 21:3029-3041.

57. Reiser J, Adair B, Reinheckel T: Specialized roles for cysteine cathepsins in health and disease. J Clin Investig 2010, 120:3421-3431.

58. Hegelund T, Celandar MC: Hepatic versus extrahepatic expression of CYP3A30 and CYP3A56 in adult killifish (Fundulus heteroclitus). Aquat Toxicol 2003, 64:277-291.

59. Kim JW, Lee Y, Kang HB, Choe YK, Chung TW, Chang SY, Kwang SL, Choe IS: Cloning of the human CDNA sequence encoding the NADH: ubiquinone oxidoreductase MLRQ subunit. Biochem Mol Biol Int 1997, 43:669-675.

doi:10.1186/1471-2148-14-7

Cite this article as: Proestou et al:: Targeted approach to identify genetic loci associated with evolved dioxin tolerance in Atlantic Killifish

(Fundulus heteroclitus). BMC Evolutionary Biology 2014 14:7.

\section{Submit your next manuscript to BioMed Central and take full advantage of:}

- Convenient online submission

- Thorough peer review

- No space constraints or color figure charges

- Immediate publication on acceptance

- Inclusion in PubMed, CAS, Scopus and Google Scholar

- Research which is freely available for redistribution 